\title{
THE EFFECT OF THE DECLINE ON POTTERY IN GHANA AND SOCIO-ECONOMIC IMPLICATIONS ON POTTERS
}

\author{
S. Nortey* And E. Asiamoaso \\ (Department of Industrial Art, Kwame Nkrumah University of Science and Technology, Kumasi, \\ Ghana).*Corresponding author's email: sammynort@gmail.com
}

\begin{abstract}
Demand for pottery in Ghana is declining according to empirical studies and this has socio-economic implications on the potters. The perpetuation of the potter's trade is vital to maintaining and preserving humankind's culture and livelihood. This paper used qualitative and quantitative approaches to discuss the effect of the decline in pottery and its socio-economic implications on potters. The study sampled 500 practising potters from four centres in Ashanti and Bono regions of Ghana; Appiadu, Pankrono, Afari and Tanoso. Findings showed that there has been a decline on pottery in Ghana which inadvertently has socio-economic implications on the potters. The study established that there has been a decline in pottery activities. Analyses revealed that there is an appreciable socio-economic variance between potters who solely depended on pottery as opposed to others who combined it with other jobs. Location was a highly influential factor in determining the potters' economic condition $(\mathrm{p} \leq 0.05)$. The effect of the declining demand on retention was highly significant in terms of potter's willingness to quit or remain in the industry $(\mathrm{p}<0.05)$. The paper recommends teaching artists must intervene in developing the skills of these potters, a development of traditional in-depth design exploration through workshops.
\end{abstract}

Keywords: Pottery, socio-economic effect, pottery centres, potters, clay

\section{Introduction}

The abundance of clay deposits in many parts of Ghana assisted in establishing many pottery centres. Pottery in its totality refers to the type of indigenous wares which are produced within the locality of any country. The production of pottery does not to an extent require any sophisticated tools or equipment such as extruders and refractory kilns but very simple and affordable tools. Predominantly, the green wares are fired at low temperatures between $600^{\circ} \mathrm{C}-850^{\circ} \mathrm{C}$ and mostly unglazed (Hopper, 2000; Humphrey, 2006). Various techniques including burnishing, incisions and smoking are used to decorate these wares.

Pottery is of significance because it demonstrates traditional manufacturing techniques which use unsophisticated technologies in producing wares and has been a source of survival for many families in Ghana. Pottery practices have contributed significantly to archaeological discoveries and theory through investigations of technological style (Childs, 1991; Lechtman, 1977), and the transmission of knowledge within communities of practice (Bedaux, 2000; David et al., 1991; Gosselain, 2000; Walde et al., 2000; Wallaert-Pêtre, 1999, 2001). 
Pottery has seen some improvement over the years, in the various shapes and techniques of production and products from the northern to the southern part of Ghana have some common characteristics in terms of shape. The dynamics of the profession are controlled by internal and external factors to the centres in which it is practised. Important internal factors include the raw material supply and attitudes of potters which are somewhat influenced by education (Browne, 1981). The external factors are normally based on product demand.

The twenty first century heralded a whole new era for the work of pottery. The large pottery industry increased production greatly with improved mechanical and technological methods, but at the same time decreased price and low patronage. By observations the number of potters who can make a living off their trade has decreased drastically in the last decades and this has called for some potters relying on other jobs. Probably the reason is that the demand for functional pottery has been diminished by an increased supply of mass-produced industry-made ceramics. Currently, there is the influx of very affordable plastic plates, bowls and cups from Asian countries which are in demand. The perpetuation of the potter's trade is vital to maintaining and preserving humankind's culture as well as providing livelihood. Although pottery may have had different functions in different communities, and at distinct times in the same communities, it obviously had, and still has, a major impact on people's lives. Pottery has not only assumed a utilitarian role, for instance in the preparation and storage of food and beverages, but clay pots and figurines have also served ritual and medical purposes (Barnett \& Hoopes, 1995).
In sub-Saharan Africa, pottery is invested with great symbolic importance. People make metaphoric use of pottery vocabulary to refer to transformations from wet to dry, soft to hard, raw to cooked, natural to cultural, impure to pure through the operation of heat, to mark isolation and destruction, to designate bodily cavities, or to discuss concepts such as spirit, conception, and essence (Barley, 1994; Gosselain, 1998; Jacobson-Widding, 1992). Moreover, "pottery traditions are "socio-technical aggregates", an intricate mix of inventions, borrowed elements, and manipulations that display an amazing propensity to redefinition by individuals and local groups' (Gosselain, 2000). A potter's technical behaviour thus leaves room for choices both along functional and/or symbolic lines, creating multifaceted associations between technological styles and social identity.

This means that through our pottery, the distinctive cultural identity is sustained and obviously an active production process will play an influential role in the socio-economic development of potters. The study therefore looks at the effect of the decline in pottery on practising potters, in terms of demand on the potters' socio-economic status. Also, to establish the relationship between the decline in pottery production, the rate of practising potters leaving the sector and study factors that influence one's decision of quitting the industry.

\section{Clay processing}

The processing of clay for the traditional potter involves careful processing of the clay in order to achieve homogeneity. David (1983) explains that, clay processing usually involves leaving the raw materials to dry, soak or sour for some weeks. Soaking which is done mostly in a pit is aimed at allowing the clay materi- 
al to achieve plasticity. If clay is already wet, the aim may be to give it a better workability through increasing the amount and distribution of water between particles. A long soaking time helps in increasing plasticity through $\mathrm{pH}$ alteration and the subsequent flocculation of clay particles, but such fermentation or aging process seems quite rare among Ghanaian potters. The most common way is hand sorting, as potters always remove coarse impurities such as pebbles, roots, or leaves at some point during the process (Sall, 2001). The last processing step generally consists of a thorough homogenization of the paste. This operation is mandatory in clay processing and has a determinant impact on clay workability. It may be done in different ways: kneading with the hands, trampling with the foot, or pounding with various kinds of tools and supports.

\section{Shaping and decoration}

In Ghanaian pottery, while techniques such as moulding and pounding require special tools and devices, it is especially the potter's hands and fingers that are in action during the major part of the shaping process. Observations at the study's centres revealed that other tools used for shaping are generally round or spherical: rounded off pottery sherds, pieces of calabash, pods, large seeds, nuts, shells, or spoons. Plastic decorations are made when the clay is still wet and done by grooving, incising, impressing, and appliqué. Grooving consists of tracing lines or figures on the surface of the vessel with the fingers or various tools whose ends are rounded or sharp. Incising is similar to grooving, except that the tools used have a sharp cutting edge so that clay surfaces are actually incised. The simplest is to press any kind of device or material such as fingers, natural objects, sticks, combs or carefully designed wooden or iron stamps. Gooselain (2000) also stresses that appliqué comprises all types of clay elements added onto the surface: example, coils, buttons, spikes, and human or animal figures. Besides plastic decoration, wares may also be ornamented with painting and or specific surface treatments. Ornamentation with painting treatments are newer techniques in the field and few potters engage in that. The resulting effect, after firing, is a dark red and shiny surface (Bell \& Calder, 1998).

\section{Experimental}

\section{Setting}

The study site constitutes four (4) pottery centres; Pankrono, Appiadu, and Afari located in Ashanti region and Tanoso located in the Bono region. The centres were purposively chosen for the case study because their locations have a heterogeneous population and have history of well-established pottery production and trade activities. In order to capture the true picture of the current phenomenon, the study was carried out during the dry season (November to April), because during the period there are minimal agricultural works, clay sources are accessible and firewood, the fuel for firing the vessels is drier.

\section{Population, sampling and instrumentation} Sample population for the study was five hundred out of about 700 potters working in the various centres put together. Leedy \& Ormrod, (2007) offered that in an ethnographical study of such phenomenon, fifty percent or more of the entire population is a fair sample size. The respondents had the general characteristics of being potters; although majority double as farmers, artisans and civil servant workers. The random sampling technique was used in selecting these potters from the four centres. The technique was carefully chosen because it is not bias and provides informed generaliza- 
tion. Survey and observation were used as the most appropriate data instrumentation based on Leedy \& Ormrod, (2007).

The researchers spent time as active participants' observers in the various pottery centres. In order to capture true social meaning and validate the first-hand data gathered from both current active and retired potters, a direct approach was adopted (Brewer, 2004). It is worth stating that face to face interview approach was conducted at the study's pottery centres using their native 'akan' language. A well-structured survey was used in the gathering of data using closed ended questions and the likert scale type. The likert scale is an ordered, one-dimensional scale from which the respondents choose one option that best aligned with their view.

The structured survey was made up of three sections. Section A was the respondent's background which included the gender, age, location, educational level and occupation. The section B sought data on the pottery activities and its effects on the socio-economic lives of the practising potter. Among the various questions raised were their income levels, whether the profession is still lucrative, availability of market, and the effect of the activities on their socio-economic lives. The section $\mathrm{C}$ sought to capture the trend of activities and the effects on quitting the profession. Questions under this section touched on the rate of quitting the profession and factors influencing such decisions.

\section{Analysis}

Both descriptive and inferential statistics were used in the analysis. The ordered logit model was used to estimate the effect of the pottery decline on socio-economic status. The study estimated the odds ratio (OR) associated with the impact of the declining pottery activities using the ordered logistic regression model. The covariates used were age, gender, location, level of income, occupation, education and pattern of pottery demand. For the qualitative findings, the results were interpreted based on themes, overall synthesis and generalizations.

\section{Results and discussion}

General overview

500 potters were randomly selected from four sites in the middle belt of Ghana (Ashanti and Brong Ahafo). Of the sample, 429 representing $85.80 \%$ were females and 71 representing $14.20 \%$ were males. This confirms Osei (1971) and Schildkrout \& Keim (1990) findings that the pottery industry is largely a female profession. In terms of age, 25-35 age group has 4 respondents $(0.80 \%), 36-45$ age bracket has 29 respondents $(5.80 \%)$, for the $46-55$ age bracket there were $180(36.0 \%)$ and above 56 years' old there were 287 (57.40\%). Afari had 112 (22.40\%) potters, $98(19.60 \%)$ potters were working at Appiadu, 170 (34.0\%) were from Pankrono and 120 (24\%) were from Tanoso near Sunyani in the Brong Ahafo region.

\section{Pottery in Ghana}

Data gathered from interviews and subsequent observations clearly indicated that pottery is drastically declining. At Appiadu and Pankrono in the Ashanti region, which are pottery towns that used to practise pottery as the main profession, the inhabitants have drifted to other professions which they now comparatively consider as lucrative. Personal communications from a significant number of elderly retired potters who actively practised the profession confirmed that it is no longer rewarding due to low demand. Some of the respondents 
mentioned that the youth are no longer interested. This finding is parallel to that of Osei (1971) who worked on pottery in Appiadu and reported that it was a flourishing profession and full of youth. Undoubtedly, the potters opined that the last decades have been particularly challenging, due to the massive introduction of plastic and metal containers, social and economic upheavals, the development of tourism and urban lifestyle, and the geographic extension of individual movements. At the various centres, functional pottery such as earthenware bowls, cooking pots are the most massively produced items as they provide the cheaper, or even the only way to keep up the business (see Figs. $1 \mathrm{a} \& \mathrm{~b}$ ). Of all the centres, there was just a shed where both functional and artistic ceramics are produced. The potters remarked that when they produce functional objects such as earthenware bowls and pots, they earn less per piece than the contemporary decorative pieces. However, these contemporary decorative pieces do not sell quickly or as often since they are mostly expensive.
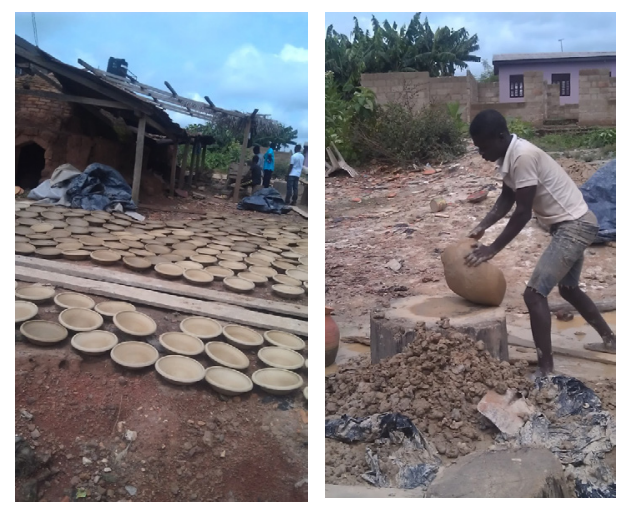

Fig. 1a \& b: ${ }^{a}$ Newly made earthenware bowls being dried; ${ }^{b}$ A potter kneading his clay

Source: Fieldwork

\section{Manufacturing process}

The qualitative approach revealed that the various centres used the same process of producing wares. These processes are clay winning, processing, shaping, decorating, drying, and firing as noted by Gosselain (2000). While most of these stages are mandatory, some such as decoration and post firing are optional, although these are widely recorded across the continent.

Ghanaian potters mostly prospect for their clay within a $3 \mathrm{~km}$ radius from the place where they live or practise their pottery (Osei, 1971). The present study revealed that prospecting for clay now is beyond this $3 \mathrm{~km}$ radius. Architectural buildings have been constructed on clay sites and some potters have to go beyond $7 \mathrm{~km}$ to prospect for clay. This obviously has cost implications. In this vein, they have a pit close to the working site where the clay is kept for seasoning. These practising potters predominantly adopt the surface mining approach because they lack sophisticated equipment for underground mining. It is worth noting that the mining of clay and its transportation involves some series of religious acts such as pouring of libation amid prayers. Gooselain (2000) contribution to the selection and exploitation of clay sources are also surrounded by a series of rituals and taboos. For instance, certain persons are systematically barred from the extraction site or the places where the potters store and manipulate the clay: little girls or boys, pregnant women, and menstruating women. However, it is interesting to note that present potters sometimes ignore most of the rituals and taboos. For instance, in Ghana male and female potters in Tanoso in Sunyani work together under one shed. Can these be a factor contributing to their 
constant decline in production and market? To them, the emphasis should be on developing techniques, designs and creating the awareness or marketing of the products is the most ideal.

Socio-Economic status of Practising Potters in relation to the Pottery Decline

Table I illustrates the results of the ordered logistic regression with the socio-economic status as the dependent variable and age, gender, location of pottery business, education, demand and dependent on pottery for livelihood as the independent variables. The dependent variable, socio-economic status, was measured in an ordinal manner and ranked as very poor, poor, good, very good socio-economic status. The lower socio-economic status took a minimum value. The scale was 1 to 4 .

The results on Table I indicate that gender and age have no significant effect on a potter's economic condition; thus ( $\mathrm{p} \geq 0.05$ ). Location was highly influential factor in determining the potters' economic condition. Thus, where a person lives (rural or urban) was very significant in relation to one's economic status $(p \leq 0.05)$. As the results indicated, potters in locations such as Afari, Appiadu and Pankrono had poorer economic status as compared to those practising their profession in Tanoso (which is an urban settlement) (OR $=0.111$, $0.023,0.052$ ) for Afari, Appiadu and Pankrono respectively. Potters in these three (3) towns were experiencing low demand for their products, thus, not making enough profit as compared to their counterparts in Tanoso in an urban centre. One can attribute this to the fast growing urbanization and technology which has rendered most of these products obsolete. Also, it is very obvious that demand in the urban towns will be greater than those at the peripherals or rural settings since cash flow in urban settings is greater than the rural settings. It must, however, be noted that the odds ratio was higher for those in Afari than for Pankrono and Appiadu. This may be due to the availability of other incentive economic activities they may find since Appiadu and Pankrono are at the peripheries of the Kumasi metropolis.

TABLE 1

Ordered Logit results for Potters 'Socio-Economic Status

\begin{tabular}{|c|c|c|c|c|c|}
\hline $\begin{array}{l}\text { Explanatory variable: } \\
\text { Gender }\end{array}$ & coefficient & Std error & P-value & OR & $95 \%$ CI (OR) \\
\hline - Male & Ref. & & & & \\
\hline & .033578 & .2498151 & 0.893 & 1.034148 & .6337818 \\
\hline
\end{tabular}

Age

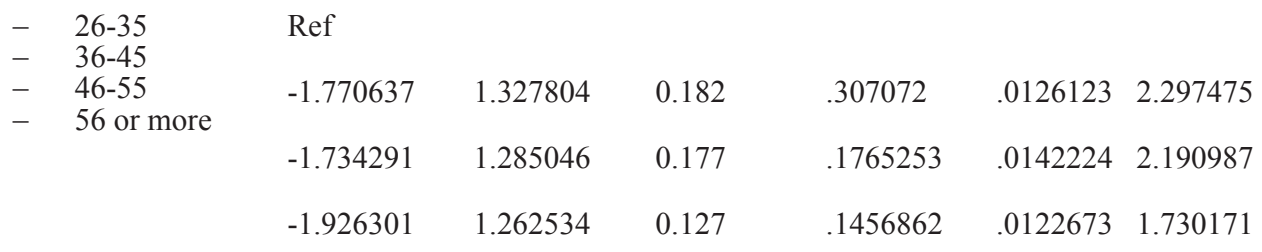


TABLE 1 (Cont'd)

Location

$$
\begin{array}{ll}
- & \text { Afari } \\
\text { - } & \text { Appiadu } \\
- & \text { Pankrono } \\
- & \text { Tanoso, Bono }
\end{array}
$$

Education

$$
\begin{array}{ll}
- & \text { Primary } \\
- & \text { JHS } \\
- & \text { SHS } \\
- & \text { Uneducated }
\end{array}
$$

$\begin{array}{lllllll}-2.197493 & .3076896 & 0.000 & .1110813 & .0607764 & .2030237 \\ -3.751463 & .3108809 & 0.000 & .0234834 & .0121422 & .0454175 \\ & & & & & & \\ -2.955649 & .3108809 & 0.000 & 2.501452 & .028298 & .0957195\end{array}$

Ref

$\begin{array}{llllll}-.2395108 & .2314824 & 0.301 & .7870128 & .4999696 & 1.238854 \\ -.5243749 & .239835 & 0.029 & .5919252 & .3699295 & .9471414 \\ & & & & & \\ 1.354329 & .7232182 & 0.061 & 3.874159 & & \end{array}$

Ref

Income $(\mathrm{GH} \phi)$

$$
\begin{array}{ll}
- & 50-250 \\
- & 251-400 \\
- & 401-600 \\
- & 600+
\end{array}
$$

Solely depend on

Pottery

$$
\begin{array}{ll}
- & \text { No } \\
- & \text { Yes }
\end{array}
$$

Pottery Demand Trend

$$
\begin{array}{ll}
- & \text { Very poor } \\
- & \text { Poor } \\
- & \text { Better } \\
- & \text { Very well }
\end{array}
$$

$\begin{array}{llllll}-3.309346 & 1.22191 & 0.007 & .0365401 & .0033318 & .4007384 \\ -2.725662 & 1.221185 & 0.026 & .0655028 & .0059812 & .7173563 \\ -3.11772 & 1.238291 & 0.012 & .044258 & .003908 & .5012176 \\ \text { Ref } & & & & .9387997 & 15.98755\end{array}$

Ref

$\begin{array}{llllll}-1.816416 & .7462923 & 0.015 & .1626074 & .0376613 & .7020783 \\ -1.814731 & .7997038 & 0.023 & .1628817 & 0339753 & .7808749 \\ -1.415653 & -1.415653 & 0.057 & .242767 & .0564883 & 1.043327\end{array}$

Ref

Number of obs $=500$, LR $_{\text {chi }}{ }^{2}(17)=211.08$, Prob chi $^{2}=0.0000$, Pseudo $R^{2}=0.1535$

Income levels and socio-economic status

Income levels of the potters were also assessed to find their input on the potters' socio- economic condition. Their net income was categorized as GH $₫ 50-250, \mathrm{GH} \varnothing$ 251-400, GH $₫ 401-600$ and above $\mathrm{GH} \phi 600$. Potters 
earning incomes between $\mathrm{GH} \phi 50$ and 600 were used as the treatment group whiles those earning higher than $\mathrm{GH} \notin 600$ were controlled. Some of the potters earned between $\mathrm{GH} \phi 50$ 250 per quarter and this represented $37 \%$ of the entire sample. Likewise, majority earned between GH $\$ 251$ and $\mathrm{GH} \notin 400$ and this represented $47.80 \%$. Few people received $\mathrm{GH} \phi 451$ and $\mathrm{GH} \phi 600$ as well as above GH $₫ 600$. These represented $14.0 \%$ and $1.20 \%$ respectively of the potters sampled. With regards to the effect on their socio-economic status, potters whose income fell within GH $\notin 50-600$ were finding it very difficult to provide themselves with basic necessities than those receiving above $\mathrm{GH} \notin 600$ per quarter. Income was statistically significant $(p \leq 0.05)$ at $95 \%$ confidence level. Thus potters whose income was below GH $\phi 600$ were more likely to experience hardships in their economic status as compared to those whose incomes were above GH $\phi 600$.

There has been a great effect that despite the amount of income received from the pottery business. The result points to a fact that even those receiving higher demand of their product and earning above GHф600 were finding it difficult to afford basic things in life such as affording a decent rented accommodation. The qualitative findings point to a fact that retired or earlier potters intimated that they received twice or thrice what current potters are receiving which was huge sum of income at that time. Traditional courtrooms, chiefs' palaces were in constant demand for these wares. The breeding or influx of the plastic industries obviously is having a great impact on the pottery industry which should not be so because the potteries made by these practising potters are uniquely made. In spite of the efforts made by potters by the assistance of Non- Governmental Organizations (NGOs) to revamp the indus- try, the challenges of imported ceramic products, the springing up of plastic industries, and low demands of wares remain a major issue. Interestingly, these trends will never change and therefore it is expedient to strengthen the pottery industry to equally compete with these other substitutes. It is worth noting that these potteries preserve the national culture and ethnic values.

\section{Dependent on pottery}

The study also found out whether sole dependent on pottery and those who had an additional source of livelihood face severity of economic conditions. By this, potters who double as farmers, artisans, civil servants were controlled whiles those whose livelihood depends on pottery alone were analysed. This grouping was also statistically significant $(\mathrm{p} \leq 0.001)$. Thus potters who do not have any other activity aside pottery were worse off $(\mathrm{OR}=0.355)$ than their counterparts who were also engaged in other ventures such as farming, trading, among others. Such people are severely affected if there is any shock in the pottery industry than potters in the controlled group.

\section{Demand on pottery}

Finally, the effect of the declining demand for pottery products was assessed. Declining demand for pottery products tended out to be a very good indicator of the economic status of potters in the sample. It was observed to be statistically significant $(p \leq 0.05)$. The declining demand for pottery products has put potters into severe economic conditions. It is affecting their markets as well as incomes. Thus, potters whose products have been experiencing very poor and poor demand were more likely to be in a severe socio-economic condition than those whose product demand have been doing well $(\mathrm{OR}=0.162)$. However, there was only a 
marginal difference between those whose demand are rated very well and those rated better $(\mathrm{p} \leq 0.057)$. This could be due to the fact that generally there is a lowering interest in pottery products.

These pottery centres are largely agrarian but rely heavily on clay resources as a source of livelihood. It was however observed that the town authorities have allocated potential clay sites for residential development and other infrastructure, thereby making it extremely difficult to locate good clay within economic haulage distances. The results demonstrate that the profession can no longer be solely depended on since those who practiced it solely are experiencing hardships than those who have other jobs in addition to the pottery profession. Da Silva Gaspar et al., (2005) confirms that since the scale of production is highly variable and seasonal, it is difficult to really rely on such activities as a reliable source of living.

\section{Declining demand and effect of quitting}

The study considered the declining demand for pottery products and whether it has had any effect on people quitting the profession. As shown clearly in Table 2, the effect of the declining demand on retention was highly significant in terms of potter's willingness to quit or remain in the industry $(\mathrm{p}<0.05)$. Potters who have been experiencing a low demand for their products are quitting the pottery business for other activities from which they can make enough money as compared to those who have not. For example, potters who have been experiencing very poor demand for their products were more likely to quit the pottery business $(p<0.001, O R=16.45)$ compared to those who have had very good demand (control group). Surprisingly, the situation was not different for potters whose demand has been somehow better.

Potters in such group were also more likely to quit the pottery business compared to those whose demand has been very good, $(\mathrm{p}<0.001$, $\mathrm{OR}=10.11)$ though $\mathrm{OR}$ was lower than that of the very poor demand group. Again, those who had poor business were not different from potters whose business has been very good in terms of their decision to quit the profession. The implication is that a sustained demand for pottery products is key to keeping industry players in business. Most potters $(89 \%$ of respondents) complained that difficulty of acquiring raw materials has a great effect on pricing affects their business because the other substitutes are comparatively cheaper. 
TABLE 2

Logit results to establish whether the decline has any effect on retention or quitting pottery

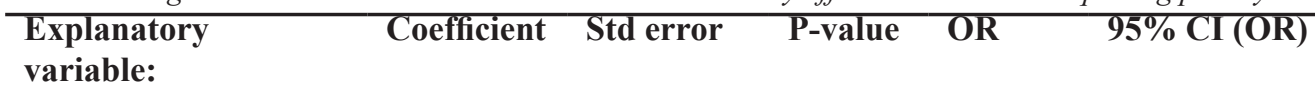

Gender

\begin{tabular}{|c|c|c|c|c|c|c|c|}
\hline- & Male & Ref & & & & & \\
\hline \multirow{2}{*}{$\mathrm{Age}^{-}$} & Female & .2874712 & .3549273 & 0.418 & 1.333052 & .6648636 & 2.672771 \\
\hline & $26-35$ & Ref & & & & & \\
\hline- & $36-45$ & -1.180673 & 1.418945 & 0.405 & .307072 & .0190297 & 4.955051 \\
\hline - & $46-55$ & .4814459 & 1.371289 & 0.726 & 1.618413 & .1101149 & 23.78661 \\
\hline- & 56 or more & .3826719 & 1.327051 & 0.773 & 1.466197 & .1087939 & 19.75969 \\
\hline \multicolumn{8}{|c|}{ Location } \\
\hline- & Afari & 1.168238 & .4208275 & 0.006 & 3.216321 & 1.409777 & 7.337842 \\
\hline- & Appiadu & 1.516418 & .4614115 & 0.001 & 4.555878 & 1.844242 & 11.2545 \\
\hline - & Pankrono & .9168714 & .3774039 & 0.015 & 2.501452 & 1.193838 & 5.241299 \\
\hline - & Tanoso, B/R & Ref & & & & & \\
\hline
\end{tabular}

Education

\begin{tabular}{|c|c|c|c|c|c|c|}
\hline Primary & -.3670515 & .3433857 & 0.285 & .692774 & .3534281 & 1.357945 \\
\hline JHS & .334018 & .3876605 & 0.389 & 1.396568 & .6532583 & 2.985654 \\
\hline SSS & -.7630619 & .8837151 & 0.388 & .4662367 & .0824872 & 2.635276 \\
\hline Uneducated & Ref & & & & & \\
\hline
\end{tabular}

Solely depend on pottery

$-\quad$ No
$-\quad$ Yes

Pottery Demand Trend

- Very poor

- Poor

.2605825

.3009662

0.387

1.297686

.7194269

2.340736

- Better

2.800278

.6813812

0.000

16.44923

4.326659

.5514386

62.53717

$.8271305 \quad .7257048$

0.254

2.286747

2.664063

9.482858

$2.313811 \quad .6806039$

0.001

10.1129

38.38898

Constant Very well

Ref $1.64393 \quad 1.64399$

0.214

Number of obs $=500$, LR $_{c^{2}}{ }^{2}(14)=44.55$, Prob $>$ chi $^{2}=0.0000$, Pseudo $R^{2}=0.0998$

Furthermore, the study revealed that the location of pottery business plays an important role in whether industry players would remain in business or not. In this case, for example, most potters in pottery centres such as Afari, Appia$\mathrm{du}$, and Pankrono are significantly quitting the pottery business as compared to potters in Tanoso, i.e. $(p<0.006),(p<0.001)$, and $(p<0.015)$ respectively. Thus potters in these communities were more likely to quit from pottery giv- en OR of 3.21, 4.55, and 2.5 respectively for Afari, Appiadu and Pankrono in comparison to potters in Tanoso located in Sunyani, even though the OR was lower for potters in Pankrono $(\mathrm{OR}=2.5)$. Qualitative findings revealed practising potters in these pottery centres have been experiencing very low demand for their products. The other study variables such as gender, education, solely dependent on pottery for livelihood, and other occupations engaged 
by the potters did not have any significant influence on potters' decision to quit pottery ( $\mathrm{p}$ $>0.05$ ). Pottery was a flourishing ancient craft and families largely depended on it booming (Haour, 2003; Barley, 2004; Bredwa-Mensa, 1996), however, this study has revealed a sharp decline in activities to the extent that there are a significant number of people quitting the profession.

\section{Conclusion and recommendations}

Ghanaian practising potters are producing very unique pottery which is akin to our cultural and ethnic values. However, its decline is having an adverse socio-economic effect on practising potters as they are quitting the profession. Currently, the potters are not satisfied with the state of their business forcing them to quit or take up other profession in addition. It is expedient that this once flourishing industry that gave livelihood to many should be saved from total collapse. Pockets of ceramic industries have sprung up but it is imperative to salvage indigenous ones. Potential clay sites must be preserved for pottery and similar product production. We must remind ourselves that the contemporary significance of the survival of the pottery industry provides exciting examples of the practise of traditional techniques. It is practical that we transform the indigenous pottery industry by repackaging their wares to add value as well as give an appropriate marketing environment for the indigenous pottery industry. The study finds expression in Nortey et al., (2013) arguing in favour of a more assertive intervention by teaching artist in developing the artistic skills of these practising potters, a development of traditional in- depth exploration, analysis, spontaneous play and association, design and revision. This should be done through periodic workshops and training. The more we do this, seeking to break the frontiers of all aspects of their production, the better the chance of these practising potters becoming competitive in this contemporary global market. There is the urgent need for the study on the determinants for the demand of pottery in Ghana in order for these practising potters to have knowledge of what goes into a consumer's decision to demand a pottery product. Practising potters can thereafter strategically produce to meet specifications.

\section{References}

Barley, N. (1994) Smashing Pots: Feats of Clay from Africa. London: The British Museum Press.

Barnett, W. K. \& Hoopes, J. W. (1995) The Emergence of Pottery: Technology and Innovation in Ancient Societies. Washington: Smithsonian Institution.

Bedaux, R.M.A. (2000) Some aspects of present-day Dogon pottery: an ethno archaeological approach. In: Roy, C.D. (Ed.), Clay and Fire: Pottery in Africa. Iowa Studies in African Art 5. University of Iowa School of Art and Art History, Iowa City, pp. $109-128$.

Bell, B. \& CALder, I. (1998) Ubumba: Aspects of Indigenous Ceramics in KwaZulu Natal, Pietermaritzburg: Natal Art Trust.

Bredwa-Mensa, Y. (1996) The Production and Use Patterns of Ga Pottery in the Lower Densu Valley, Western Accra Plains, Ghana. Papers from the Institute of Archaeology 7, 47 - 58.

Brewer, R. (2004) 'Ethnography' in D. Cassell and G. Symon (ed.), Essential Guide to Qualitative Methods in Organizational Research, London: Sage Publications, xxix \& 77.

Browne, A. W. (1981) Appropriate Technology and the dynamics of Village Industry: A case study of Pottery in Ghana, Transactions of the Institute of British Geographers 6 (3), 313 - 323. 
Childs, S.T. (1991) Style, technology and iron smelting in Bantu-speaking Africa. Journal of Anthropological Archaeology 10, 332 - 359.

Da Silva Gaspar, L., Gosselain, O. P., Livingstone Smith, A. \& Elhadi, N. (2005) Potières et poteries de Dia. Recherches archèologiques a Dia dans le Delta intèrieur du Niger (Mali): bilan des saisons e fouilles

David, M. (1983) Poterie domesstique et rituelle du Sud-Benin: etude ehnoarchèologique. Archives Suisses d'Anthropologie Gènèrale 47 (2), $121-184$.

David, N., Sterner, J. \& Gavua, K. (1988) Why pots are decorated? Current Anthropology 29 (3), $365-389$.

David, N., Gavua, K., Maceachern, A.s. \& Sterner, J. (1991) Ethnicity and material culture in north Cameroon. Canadian Journal of Archaeology 15, $171-177$.

Dialo, B. M. Vanhaelen, \& Gosselain, O.P. (1995) Plant Constituents Involved in Coating Practices Among Traditional African Potters. Experientia, 51, 95 - 107.

Fatunsin, A. K. (1992) Yoruba Pottery. Ibadan: National Commission for Museums and Monuments.

Gosselain, O.P. (2000) Materialising identities: An African perspective. Journal of Archaeological Method and Theory 7 (3), 187-217.

Gosselain, O.P. (1998) Social and Technical Identity in a Clay Crystal Ball in The Archaeology of Social Boundaries, edited by M. T. Stark, pp. 78 - 106. Smithsonian Institution Press, Washington, D.C.

Haour, A. C. (2003) One hundred years of Archaeology in Niger. Journal of World Prehistory 17 (2), $181-234$.
Hopper, R. (2000) Functional Pottery, (2nd edition). U.S.A: Krause Publications, p. 9.

Humphrey, J. W. (2006) Ancient Technology. U.S.A: Greenwood Press, p. 113.

JACOBSON-Widding, A. (1992) Pits, pots and snakes. An anthropological approach to ancient African symbols, Nordic Journal of African Studies $1,5-27$.

Lechtman, H. (1977) Style in technology: some early thoughts. In: Lechtman, H., Merrill, R.S. (Eds.), Material Culture: Styles, Organization, and Dynamics of Technology. West Publishing Co., St. Paul, Minnesota, pp. 3 - 20.

Leedy, P. D. \& Ormrod, J. E. (2007) Practical Research Planning and Design, ( $8^{\text {th }}$ Ed.), New Jersey: Pearson Merril Prentice.

Nortey, S., OKai, E.f. \& Bodjawah, E.к (2013) Breaking Monotony: A reflective study of teaching decorative pot making, Teaching Artist Journal 11 (2), $69-80$.

OseI, S.K. (1971) Pottery in Appiadu, Unpublished BA thesis, Department of Industrial Art, KNUST, p 8.

SALL, M. (2001) Traditions céramiques, identités et peuplement en Sénégambie. Ethnographie comparée et essai de reconstitutionhistorique. Ph.D. Thesis, Université Libre de Bruxelles.

Schildkrout, E. \& KeIm, C. (1990). African Reflections: Art from Northeastern Zaire, Seattle: University of Washington Press.

Walde, D., David, N. \& Maceachern, S. (2000) Style and the identification of artifact production systems: an explicitly scientific approach. In: Roy, C.D. (Ed.), Clay and Fire: Pottery in Africa. Iowa Studies in African Art, vol. IV. University of Iowa School of Art and Art History, Iowa City, pp. $77-108$. 
Wallaert-PÊTre, H. (1999) Manual laterality apprenticeship as the first learning rule prescribed to potters. In: Owen, L.R., Porr, M. (Eds.), Ethno-Analogy and the Reconstruction of Prehistoric Artefact Use and Production. Mo Vince Verlag, Tubingen, pp. $185-206$.
Wallaert-PÊTre, H. (2001) Learning how to make the right pots: apprenticeship strategies and material culture, a case study in handmade pottery from Cameroon. Journal of Anthropological Research 57, $471-493$.

Received 4 Apr 16; revised 21 Jan 20. 